\title{
An improved protocol for separating meiofauna from sediments using colloidal silica sols
}

\author{
Robert Burgess*
}

University of Texas Marine Science Institute, 750 Channelview Drive, Port Aransas, Texas 78737, USA

\begin{abstract}
A new isopycnic separation technique was developed to minimize the effect of sediment granulometry on extraction efficiency of benthic meiofauna. The method uses colloidal silica Ludox ${ }^{\circledR}$ (DuPont) HS 40 as a high density solution to extract meiofaunal organisms from sediment. Previous protocols using silica sols have had problems with physical interactions between the sediment and the specimens, causing large variations in extraction efficiencies between sediment types. The procedure presented herein reduces this problem by the addition of a 5 min period of fluidization of the sediment. The time used to complete the method is minimized with a final centrifugation step, which accelerates the settling rate of the fine sediment, resulting in a total time required for separation of approximately $20 \mathrm{~min}$. Forty-eight samples were processed, with sediments ranging from sand to silty clay. The average extraction efficiency was $96.8 \pm 3.9 \%$ for the total meiofaunal abundance. Extraction efficiency was independent of sediment granulometry over the range of sediments tested.
\end{abstract}

KEY WORDS: Meiofauna $\cdot$ Isopycnic separation $\cdot$ Flotation separation $\cdot$ Silica sol $\cdot$ Ludox $^{\circledR}$ technique Resale or republication not permitted without written consent of the publisher

\section{INTRODUCTION}

All separation techniques used on preserved meiofauna, whether a simple swirl and decant method or isopycnic separation protocols, rely on the differences in density between the sediment and the meiofauna to effect separation. Isopycnic separation techniques have been shown to be broadly applicable for separating many types of biological specimens and have been employed to separate biological materials for over $40 \mathrm{yr}$ (Iler 1979). In the late 1960s silica sols became very popular for isopycnic separation of subcellular organelles and bioactive molecules (Pertoft \& Laurent 1969). Benthic ecologists started to develop protocols for using silica sols in the late 1970s (de Jonge \& Bouwman 1977). Isopycnic separation using silica sols have been shown to be the fastest separation technique for benthic samples, saving up to $40 \%$ of the time needed to process a sample over sieving and decanting techniques (Nichols 1979, Giere 1993). However, along

\footnotetext{
*E-mail: burgess@moment.net
}

with all the advantages of using colloidal silica, there are also some distinct disadvantages. First, there are many grades of commercially available silica sols, each with its own characteristic chemical properties. More importantly, previous techniques have had large variations in extraction efficiencies in different sediment types.

While only Ludox ${ }^{\circledR}$ (DuPont) HS 40 was used in this study, several available sols would have been appropriate to use. The choice of an appropriate sol depends on 2 factors: necessary chemical properties, and price. In 1998, the prices of silica sols ranged from approximately $\$ 11 \mathrm{US}^{-1}$ for unmodified sols, to approximately \$201 US l $^{-1}$ for Polyvinylpyrrolidone (PVP)-coated sols (Sigma Chemical 1998 Pricing Catalog). Unmodified silica sols are very sensitive to divalent cations such as calcium or magnesium, which are present in large quantities in brackish and marine waters. Upon exposure to divalent cations, unmodified silica sols quickly gel due to the formation of covalent silaxane bonds, which trap the specimens in a white jelly of insoluble silica crystals (Iler 1979). This can be prevented by using a freshwater pre-wash before the addition of the 
sol, or by using a more expensive modified sol. Aluminate stabilized sols are more resistant to gelling due to the exposure to divalent cations, and can be used on brackish water samples without a pre-wash (Price et al. 1978), but are approximately $10 \%$ more expensive than unmodified sols (Sigma 1998). PVP-coated aluminate sols (Percoll ${ }^{\circledR}$, Pharmacia fine chemicals, Uppsala, Sweden) are required to work at oceanic salinities (Iler 1979). However, their high cost limits their application for general ecological work.

The original protocols using silica sols were for subcellular organelles and bioactive molecules (Pertoft \& Laurent 1969). The intent of this type of protocol was to separate many types of subcellular particles, which differed only slightly in density from each other. Therefore, a density gradient was used, which caused specimens of similar density to form distinct bands in the gradient. Benthic ecologists seem to have retained this paradigm of separating many groups of similar density. Their procedures also use density gradients, or alternatively the density of the sol was adjusted to be close to the density of the meiofauna (de Jonge \& Bouwman 1977, Nichols 1979, Schwinghamer 1981). However, benthic samples really only have 2 major groups to separate, which have large differences in specific gravity. Minerals make up the largest proportion of benthic samples, and have specific gravities ranging from approximately 2.5 to 2.8 (Weast 1965). The meiofauna are much less dense, having a specific gravity near 1.15, and make up only a very small fraction of the total volume of the sample (Price et al. 1978). Separation of meiofauna occurs when the density of the solution is above the density of the meiofauna but below the density of the minerals. Since commercially available sols have a specific gravity at full strength of 1.2 to 1.4 (Dupont 1995), there is no need to use a diluted solution for separation to occur. In the full strength sol, the animals simply float out of the sediment and continue to rise until they reach the top of the sol. The supernatant containing the meiofauna can then be poured onto a sieve, eliminating the labor intensive and tedious process of looking for animals buried in the fine sediment, which commonly remains after sieving and decanting techniques.

Quantitative studies have an additional requirement of a separation technique, the extraction efficiency must be constant throughout the samples of the study. Past isopycnic protocols have been shown to have large variations in extraction efficiencies in different sediment types. It was proposed that the variations were the result of physical interactions between the sediment and the specimens (de Jonge \& Bouwman 1977, Nichols 1979, Barnett 1980). Therefore, it was suggested that extraction efficiencies should be checked for each sediment type when using isopycnic separations for quantitative extractions (Schwinghamer 1981). This presents a problem for most ecological studies, because there are frequently many sediment types in one study. The use of a technique with variations in extraction efficiency complicates between-site comparisons, since the extraction efficiency of each sediment type would have to be factored into the analysis. De Jonge \& Bouwman (1977) suggested that the variations in separation efficiency in different sediments could be due to entrapment of organisms by sediment particles. Their solution was to slowly stir the sediment in a high density mixture for $16 \mathrm{~h}$. Nichols (1979) found that nematodes could be more efficiently extracted from salt marsh mud if the sediment was poured on top of a column of sol, which had been adjusted to a density near that of meiofauna. This would allow the silt and sand fractions, which have a much higher specific gravity, to sink out slowly, and thereby minimize specimen entrapment. However, the process is slow, taking 6 to $24 \mathrm{~h}$ to complete, and it is awkward to recover the specimens from a column without disturbing the sediment pellet. Both of these methods are effective in limiting entrapment, but they require extensive sample handling which results in losses of animals in each step. They also have long separation intervals, and use relatively large volumes of silica sol.

In this paper, I outline a fluidization protocol that minimizes the problems of physical interactions of sediment with specimens, while reducing the amount of silica sol solution required for separation, as well as reducing the time required for separation. The new protocol has been shown to produce excellent extraction efficiencies of $96.8 \pm 3.9 \%$ of the entire meiofaunal community abundance with one extraction cycle from sediments ranging from sand to silty clay.

\section{MATERIALS AND METHODS}

Forty-eight cores were examined from Corpus Christi Bay, Texas, USA, and the Texas continental shelf. The cores were $1.9 \mathrm{~cm}$ in diameter by $2 \mathrm{~cm}$ deep (ca 18 $\mathrm{ml})$. The cores from Corpus Christi Bay were collected by a diver, and the continental shelf cores were collected with a coring tube secured within a covered boxcore. Sediment analysis was done on duplicate samples taken at the same time and place as the meiofauna cores and were recorded as percent sand, silt and clay. The meiofauna samples were placed into $50 \mathrm{ml}$ disposable polypropylene centrifuge tubes in the field, and preserved in $3 \%$ formalin buffered with filtered seawater.

Ludox HS 40 with a density of $1.31 \mathrm{~g} \mathrm{~cm}^{-3}$ was chosen for the extraction. Although it is sensitive to divalent cations in seawater, it only costs $\$ 11 \mathrm{US} \mathrm{l}^{-1}$ (Iler 1979, Sigma 1998). To prevent gelling of the Ludox, the 
saltwater-formalin solution was poured off and the sample rinsed on a $63 \mu \mathrm{m}$ sieve. The contents of the sieve were washed back into the tube with as little freshwater as possible. Approximately $30 \mathrm{ml}$ of Ludox was added to the sample tube, resulting in a total sample volume of approximately 40 to $45 \mathrm{ml}$. It was important to leave an air space in the centrifuge tube so the sample could be thoroughly mixed.

A variable speed vortex mixer set at maximum speed was used to mix the sample with the Ludox solution for $30 \mathrm{~s}$. This step may seem deleterious to fragile specimens, but no excessive damage was noticed in any samples. The centripetal acceleration imparted by the mixer on the sample was then slowly decreased until the heavy sand and shell hash could be observed falling out of suspension. However, acceleration was maintained just high enough so that the sediment at the bottom of the tube remained fluidized. This fluidized state could be ascertained by the formation of bands due to the separation of different densities of the mineral constituents in the sediment. The samples were then left on the vortex mixer at slow speed for $4 \mathrm{~min}$. The animals, being lighter than both the sediment and the sol, floated up through the fluidized sediment and continued to rise to the surface of the sol. A mechanical finger was created to hold the sample tube in the vortexer during this step. The finger was fabricated from a stainless rod with a $90^{\circ}$ bend, and tipped with a No. 4 rubber stopper. The finger was then clamped on a ring stand at the appropriate height to hold the sample in the vortex mixer.

The samples were then centrifuged at $900 \times g$ for 5 min (the $g$ force was calculated for the bottom of the tube). The density distribution is not affected whether viewed in a stationary or an accelerating reference frame because silica sols will not centrifuge out at this relatively low $g$ force. Therefore, centrifugation was employed only to speed the sedimentation of the fine silt and clay, and to firmly pellet the sediment in the bottom of the tube. The meiofauna and the sol were then poured onto a $63 \mu \mathrm{m}$ sieve over a storage jar. The jar was immediately capped so that the used sol would not desiccate and it could be reused. The underside of the lid and the inside walls of the centrifuge tube were then washed on to the sieve with freshwater, taking care not to disturb the pellet. The contents of the sieve were washed with freshwater to remove any remaining Ludox from the sample. For this study, the pellet was also washed to remove any residual Ludox to prevent gelling before the pellet could be examined. Only 1 extraction cycle was used to separate the specimens from the sediment. The animals from both the supernatant and the sediment pellet were sorted under a dissection microscope to major taxa and enumerated.

The used sol was recycled to do extractions in another study. The used sol retained its high density because as little water was added to the original sample as possible. However, the used solution had a slightly lower specific gravity due to absorption of water contained in the original sample. The density of the solution was monitored with a hydrometer, and sieved again before reuse. This extraction method, using the diluted Ludox solution, retained its effectiveness for up to 3 more extraction cycles before the absorption of water from samples had decreased the density to near $1.15 \mathrm{~g} \mathrm{~cm}^{-3}$ (Jarvis pers. comm. 1998).

\section{RESULTS AND DISCUSSION}

Percent of meiofauna extracted was calculated for each sample as the number extracted by the sol divided by the total number found in the sol and the pellet. A mean and standard deviation were calculated for each taxon (Table 1). Most taxa had greater than $95 \%$ average extraction efficiencies. However, this was not the case for Foraminifera, which only had a mean extraction efficiency of $88 \%$. The higher average retention of Foraminifera in the sediment may have been due to their large calcite tests, which have a density of 2.7 , and therefore greatly increase their overall density (Weast 1965). Meiofaunal sized bivalves also had an average

Table 1. Mean extraction efficiencies, and the standard deviation. $\mathrm{n}=$ number of samples containing the taxon

\begin{tabular}{|lrcr|}
\hline Taxon & $\mathrm{n}$ & $\begin{array}{c}\text { Mean extraction } \\
\text { efficiency }(\%)\end{array}$ & $\mathrm{SD}$ \\
\hline Nematoda & 48 & 97.4 & 2.2 \\
Harpacticoida & 39 & 96.0 & 10.0 \\
Cyclopoida & 10 & 98.6 & 4.5 \\
Calanoida & 2 & 100.0 & 0.0 \\
Harpacticoid nauplii & 38 & 99.5 & 2.7 \\
Turbellaria & 35 & 99.2 & 3.0 \\
Polychaeta & 41 & 99.8 & 1.1 \\
Bivalvia & 29 & 95.9 & 18.6 \\
Gastropoda & 12 & 100.0 & 0.0 \\
Foraminiferida & 46 & 87.8 & 19.1 \\
Nemertea & 18 & 98.6 & 5.9 \\
Ostracoda & 32 & 99.3 & 2.8 \\
Tanaidacea & 2 & 100.0 & 0.0 \\
Kinorhyncha & 18 & 99.7 & 1.3 \\
Tardigrada & 7 & 100.0 & 0.0 \\
Gastrotricha & 9 & 99.8 & 0.4 \\
Unknown & 47 & 98.8 & 3.5 \\
Total & 48 & 96.8 & 3.9 \\
\hline
\end{tabular}




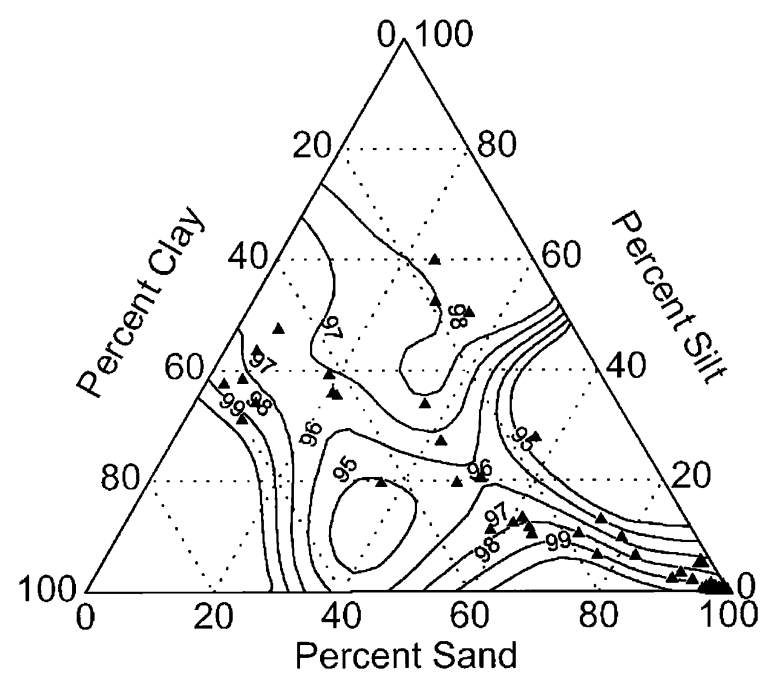

Fig. 1. Percent meiofauna extracted in different sediment types

extraction efficiency that was lower than the mean extraction rate, which is most likely also due to their calcite shell, but the efficiency was still over $95 \%$.

Sand, silt, and clay composition of the sediments were plotted on Shepard's (1961) triangular coordinate diagram for clastic sediments. In these diagrams, a sediment's clastic composition is described by the percentages of sand, silt, and clay that makes up that sediment. For any point on the graph the sand, silt, and clay percentages necessarily add up to $100 \%$. Extraction efficiencies were plotted as a fourth axis to visualize any trends relating to composition of the sediments.

Samples had a mean of $661 \pm 466$ meiofauna specimens. The extraction efficiency of the total meiofaunal

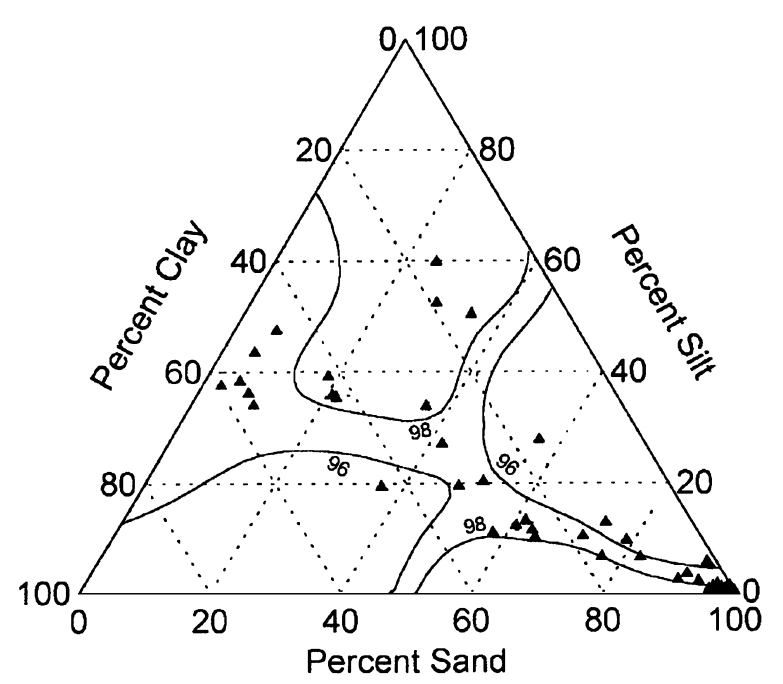

Fig. 2. Percent nematodes extracted in different sediment types community exhibited no major trends with sediment type (Fig. 1). Similarly, the extraction efficiency for nematodes, the most numerous taxon $(454 \pm 350$ specimens sample $\left.{ }^{-1}\right)$, was also very uniform with sediment type (Fig. 2). Harpacticoid copepods averaged only 16 \pm 24 animals in a sample. Nine samples which contained no harpacticoids, and 5 samples containing 2 or less, were not plotted in Fig. 3. The extraction efficiency for harpacticoids in the remaining 34 samples was also very uniform with sediment type (Fig. 3). No significant relationship between sediment granulometry and extraction efficiency was found at the $5 \%$ level using either linear or logistic multiple regression techniques.

Extraction efficiencies using this technique showed little change over a range of sediment types from sand to silty clay. However, there were no samples containing greater than $60 \%$ silt or clay. Therefore, the extraction efficiency of this technique needs to be tested before use on sediments outside the tested limits. Some preliminary work has been done with sediments from an English estuary that contained considerable amounts of organic detritus. While the extraction efficiencies of meiofauna remained high in these samples, the technique carried over the detritus because it has a density close to meiofauna (Jarvis pers. comm. 1998).

Acknowledgements. Collection of the samples was supported by The Corpus Christi Bay National Estuary Program under contract number 72-000000-01, Texas A\&M University Sea Grant project R/ES-74, and The National Fish and Wildlife Foundation contract NBR:97-156-005. I would like to thank Dr Steve Jarvis for his laboratory and editorial assistance on this manuscript, and Dr Lee Fuiman for his help with multiple logistic regression analysis.

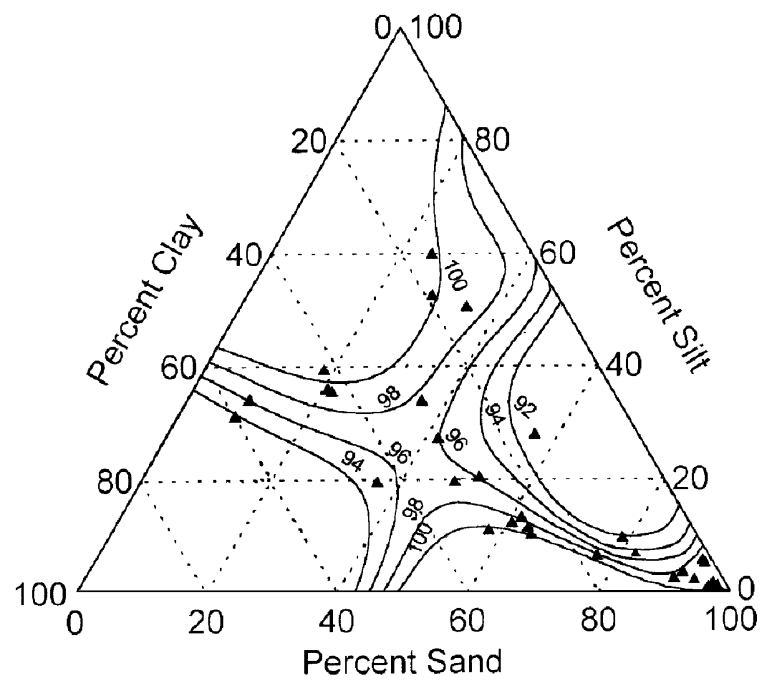

Fig. 3. Percent harpacticoids extracted in different sediment types 


\section{LITERATURE CITED}

Barnett BE (1980) A physico-chemical method for the extraction of marine and estuarine benthos from clays and resistant muds. J Mar Biol Assoc UK 60:225-256

De Jonge VN, Bouwman LA (1977) A simple density separation technique of quantitative isolation of meiobenthos using colloidal silica Ludox-TM. Mar Biol 42:143-148

Dupont (1995) Ludox colloidal silica, properties, uses, storage, and handling. EI Du Pont de Nemours and Co, Industrial Chemicals Department. Product Information Bulletin \#H47771-2. Wilmington, DE

Giere O (1993) Meiobenthology, the microscopic fauna in aquatic sediments. Springer-Verlag, Berlin

Iler R (1979) The chemistry of silica, solubility, polymerization, colloid and surface properties, and biochemistry. Wiley-Interscience Publication, NY

Editorial responsibility: Otto Kinne (Editor),

Oldendorf/Luhe, Germany
Nichols JA (1979) A simple flotation technique for separating meiobenthic nematodes from fine grained sediments. Trans Am Microsc Soc 98: 127-130

Pertoft H, Laurent TC (1969). Use of silica sols. In: Gerritsen T (ed) Modern separation methods of macromolecules and particles, Vol 2. Wiley-Interscience, NY, p 71-96

Price CA, Onge-Burns JM, Colton JB, Joyce JE (1978) Automatic sorting of zooplankton by isopycnic sedimentation in gradients of silica. Mar Biol 42:225-232

Schwinghamer P (1981) Extraction of living meiofauna from marine sediments by centrifugation in a silica sol-sorbitol mixture. Can J Fish Aquat Sci 38:476-478

Shepard FP (1961) Deep sea sands. Reports from the 21st International Geological Congress, Norden 1960, 23: $26-42$

Weast RC (ed) (1965) CRC Handbook of chemistry and physics, 46th edn. Chemical Rubber Company, Cleveland, OH

Submitted: June 13, 2000; Accepted: October 12, 2000 Proofs received from author(s): March 28, 2001 